Brief Report

\title{
Weight status or weight stigma? Obesity stereotypes-Not excess weight-Reduce working memory in school-aged children
}

\author{
Veronica Guardabassi *, Carlo Tomasetto \\ Department of Psychology, University of Bologna, 47521 Cesena, Italy
}

\section{A R T I C L E I N F O}

\section{Article history:}

Received 9 April 2019

Revised 28 August 2019

Available online $\mathrm{xxxx}$

\section{Keywords:}

Obesity

Executive functions

Working memory

Stereotype threat

Weight stigma

Children

\begin{abstract}
A B S T R A C T
The high prevalence of childhood obesity has drawn increasing attention to the neurocognitive impairments associated with excess weight, and evidence has accumulated of a progressive decline in working memory at increasing levels of children's Body Mass Index (BMI). However, obesity is also a highly stigmatizing condition, and pervasive societal stereotypes depict individuals with obesity as less intelligent than those with average weight. For this reason, we investigated whether stereotype threat (i.e., the fear of confirming a negative stereotype attached to one's social groups) contributes to working memory impairments in children with excess weight. By applying a consolidated paradigm in stereotype threat research, primary school-age children $(N=176)$ performed a computerized working memory task that was alternatively labeled as diagnostic (i.e., stereotype-threatening) or nondiagnostic (i.e., non-stereotype-threatening) of their intellectual ability. Results confirmed that working memory decreased at increasing levels of BMI in the stereotype-threatening condition, whereas the relation between body weight and working memory was null when task diagnosticity was removed. This effect was not further moderated by children's direct experiences of weight-based stigmatization or by their personal endorsement of the obesity stereotype about intelligence. These findings suggest that vulnerability to weight-related stereotype threat emerges early in life and may contribute to working memory deficits in children with obesity.
\end{abstract}

(c) 2019 Elsevier Inc. All rights reserved.

\footnotetext{
* Corresponding author.

E-mail address: veronica.guardabassi@unibo.it (V. Guardabassi).
} 


\section{Introduction}

It is estimated that there are more than 107 million children with obesity worldwide (GBD [Global Burden of Disease] 2015 Obesity Collaborators, 2017). Childhood obesity is associated with increased morbidity and mortality during adulthood (Reilly \& Kelly, 2011) and reduced quality of life (Schwimmer, Burwinkle, \& Varni, 2003) as well as with neurocognitive impairments (e.g., Prickett, Brennan, \& Stolwyk, 2015) and deficits in executive functions (e.g., Hayes, Eichen, Barch, \& Wilfley, 2018). In addition, childhood obesity is a highly stigmatizing condition (Pont, Puhl, Cook, \& Slusser, 2017), and most of its negative health and psychological correlates do not depend on excess weight per se but instead depend on exposure to and internalization of obesity-related stereotypes, prejudice, and discrimination, that is, weight stigma (Guardabassi, Mirisola, \& Tomasetto, 2018; Juvonen, Lessard, Schacter, \& Suchilt, 2017; Zuba \& Warschburger, 2017). Here, we contend that weight stigma may also be implied in deficits in executive functions that are associated with excess weight.

Negative relations are documented between Body Mass Index (BMI) and executive functions such as inhibition (e.g., Chojnacki et al., 2018; Goldschmidt et al., 2018; Guerrieri, Nederkoorn, \& Jansen, 2008), cognitive flexibility (e.g., Goldschmidt et al., 2018; Gunstad et al., 2008; Tsai, Chen, Pan, \& Tseng, 2016), and working memory (e.g., Goldschmidt et al., 2018; Gunstad et al., 2008; Wu, Chen, Yang, \& Li, 2017), especially in tasks requiring high cognitive control (Kamijo et al., 2012). Working memory depletion has also emerged as a key mediator in the link between excess weight and poor academic achievement (He, Chen, Fan, Cai, \& Huang, 2019; Wu et al., 2017). Biological processes and health comorbidities, such as brain alterations (Bruce et al., 2010; Esteban-Cornejo et al., 2018; Ou, Andres, Pivik, Cleves, \& Badger, 2015), inflammation (Miller \& Spencer, 2014), diabetes (Li et al., 2018), sleep disorders (Kohler et al., 2018), and obesity-related behaviors (e.g., high food intake or low physical activity; Chang, Chu, Chen, Hung, \& Etnier, 2017; Song et al., 2016), may help to explain deficits in executive functions.

However, stereotypes that associate obesity with laziness, lack of self-discipline, and lower intelligence (Latner, Simmonds, Rosewall, \& Stunkard, 2007) may also interfere with the assessment of executive functions in children with obesity. Specifically, the expectation or fear of confirming negative stereotypes associated with obesity may lead to a systematic overestimation of obesity-related cognitive deficits. This phenomenon, referred to as stereotype threat (Spencer, Logel, \& Davies, 2016; Steele \& Aronson, 1995), has been proved to school-age girls proficiency in mathematics (Ambady, Shih, Kim, \& Pittinsky, 2001), boys' performance in reading (Pansu et al., 2016), and African American and Latino children's scoring on verbal intelligence tests (McKown \& Strambler, 2009).

Stereotype threat appears to interfere with executive functions among adults with obesity by lowering inhibitory control (Major, Eliezer, \& Rieck, 2012) and working memory (Guardabassi \& Tomasetto, 2018) when stereotype-related concerns are activated in the assessment context. In the current work, we examined, for the first time, whether a negative association between BMI and working memory (i.e., a decrease in working memory associated with higher levels of BMI) emerges among children with obesity when working memory tasks are labeled as an assessment of stereotype-related cognitive abilities (i.e., as an intelligence test) as compared with when the same tasks are labeled as nondiagnostic tools (i.e., when stereotype threat is removed) (Hypothesis 1 [H1]). Expanding the focus of research to middle childhood is important because middle childhood is a life period that is rich in cognitive, biological, and social-emotional changes that reverberate into subsequent psychological development (see Eccles, 1999). Unfortunately, literature on the consequences of weight stigma during childhood is relatively scant despite the fact that weight-based stigma experiences are highly prevalent among children (Di Pasquale \& Celsi, 2017), and prospective studies suggest that exposure to weight stigma during middle childhood negatively affects psychological functioning over time (Pont et al., 2017).

In addition, literature highlights that individuals vary in their susceptibility to stereotype threat. Exposure to stigma experiences, or personal endorsement of negative group stereotypes, may increase individuals' vulnerability to stereotype-threatening environments (Brown \& Pinel, 2003; Spencer 
et al., 2016). Accordingly, we investigated whether experiences of weight stigmatization (e.g., being teased by peers due to one's overweight) (Hypothesis 2 [H2]) and personal endorsement of the intelligence obesity stereotype (Hypothesis 3 [H3]), strengthen the negative relation between children's BMI and working memory under stereotype threat.

\section{Method}

\section{Participants and procedure}

Participants were 176 primary school children (106 boys), mostly born in Italy ( $n=173)$, attending the third, fourth, or fifth grade $\left(M_{\mathrm{age}}=116.07\right.$ months, $\left.S D=10.43\right)$. After approval from the local university ethical committee was received and parental informed consent was obtained, participants were selected from a larger sample of children $(N=1292)$ participating in a broader survey. During this screening phase, both children and parents filled out a paper-and-pencil questionnaire on obesity and psychological functioning. For the purpose of this study, we retained only measures concerning children's weight-based teasing experiences and stereotypes as well as parent-reported children's weight and height. In detail, all children with obesity (i.e., with estimated standardized BMI [zBMI] based on parental reports: $\geq 95$ th percentile according to the World Health Organization's [WHO] growth charts) (Onis et al., 2007) were retained $(n=63)$. For each child with obesity, one or two age- and gender-matched classmates with average weight ( $z$ BMI: 5th-84th percentiles) and, where available, one classmate with overweight ( $z$ BMI: 85th-94th percentiles) were also recruited (see Appendix A for more details).

Within 3 weeks of their selection, participants were interviewed individually in a quiet room at their school. Children's weight and height were assessed through a precision scale and stadiometer to obtain objective anthropometric data to be used for all subsequent analyses. Children were then randomly assigned to either a stereotype-threatening (ST) condition or a non-stereotypethreatening (NST) condition to stress or minimize the stereotype-related diagnosticity of a computer-based working memory test. ${ }^{1}$ In the ST condition, the working memory task was labeled as a test to assess intelligence $(n=86)$. In the NST condition, the same task was labeled as a nondiagnostic computer game $(n=90)$. See Appendix B for more details on experimental instructions.

\section{Measures}

Body weight

Sex- and age-adjusted $z$ BMI was computed according to the WHO computation formula (Onis et al., 2007).

\section{Working memory}

The $N$-back task (Jaeggi et al., 2010) was used to assess working memory. Children needed to press a keyboard key when a letter displayed in the center of the screen matched the letter they saw at the beginning of the task (N0), in the precedent position (N1), or in the two precedent positions (N2). After instructions, participants received one practice trial and three blocks of stimuli per level of difficulty.

\section{Stigma experiences}

The Perception of Teasing Scale (POTS; Thompson, Cattarin, Fowler, \& Fisher, 1995) was used to assess the frequency of weight-related teasing episodes experienced by peers. The POTS scale consisted of six items (e.g., "People called you names like 'fatso"”) with a 5-point Likert scale from never to very often $(\alpha=.84)$.

\footnotetext{
${ }^{1}$ A child-friendly version of the probabilistic selection task (Frank, Seeberger, \& O'Reilly, 2004) was also included in the experimental protocol as a measure of probabilistic learning. Because probabilistic learning is unaffected by working memory load, we expected and found that children's performance was unaffected by BMI, stereotype threat manipulation, and their interaction. Due to space limit concerns, this measure is not further discussed in this article.
} 


\section{Obesity stereotype endorsement}

The Obesity Stigmatization Questionnaire (Latner et al., 2007) was adopted to evaluate explicit attitudes about body weight. Children rated their agreement with five statements concerning the figure of a child with excess weight using a 10-point Likert scale. For the purpose of this study, we retained only one item concerning intellectual ability, with higher values indicating stronger personal endorsement of the intelligence stereotype.

\section{Data analyses}

We used a linear mixed-effects model with SPSS 25 software to test our hypotheses. Fixed effects were condition, BMI, and their interaction term as between-participants factors and the three levels of difficulty of the $\mathrm{N}$-back task as a within-participant factor. Random effects for participants' class $(n=54)$ and $N$-back levels were included in the model to account for nonindependence in the data structure. The Akaike information criterion (AIC) and the Bayesian information criterion (BIC) were used to evaluate whether the inclusion of potential moderators (i.e., weight-based experiences of discrimination [H2] and endorsement of obesity's stereotype on intelligence [H3]) improved the fit of the model. An increase or decrease of more than 2 units in AIC and BIC is indicative of a nontrivial worsening or improving in model fit, respectively (Raftery, 1995).

\section{Results}

Table 1 displays descriptive statistics and bivariate correlations. Stigma experiences were more prevalent at increasing levels of $z \mathrm{BMI}(p<.001)$. Endorsement of the obesity stereotype about intelligence was unrelated to $z$ BMI $(p=.830)$.

Results from the mixed-effects model revealed that the main effects of $N$-back difficulty, $F(2$, $198.70)=43.43, p<.001$, and $z$ BMI, $F(1,153.07)=5.46, p=.021$, were significant, whereas the main effect of condition was not, $F(1,153.07)=3.14, p=.079$. More important, as expected (H1), the twoway interaction between $z \mathrm{BMI}$ and condition was significant, $F(1,153.07)=5.07, p=.026$, indicating that the relation between body weight and working memory varied depending on the presence of stereotype threat. This effect was not further qualified by the three-way interaction among $z \mathrm{BMI}$, condition, and $N$-back difficulty, $F(2,198.70)=0.60, p=.548$, suggesting that the impairing effect of stereotype threat on the relation between $z \mathrm{BMI}$ and working memory did not vary in strength or direction at different levels of task difficulty. Two-way interactions between $N$-back levels and $z \mathrm{BMI}, F(2$, $198.70)=1.085, p=.340$, and between $N$-back levels and condition, $F(2,198.70)=1.456, p=.236$, were also nonsignificant. As is evident from Fig. 1, simple slopes analyses revealed that working memory scores declined by 0.35 standard deviations per unit of increase in children's $z$ BMI in the ST condition. In contrast, the relation between $z \mathrm{BMI}$ and working memory was null in the NST condition.

Regarding the role of potential moderators ( $\mathrm{H} 2$ and $\mathrm{H} 3$ ), the interaction between participants' $z \mathrm{BMI}$ and condition was not further qualified by either weight-based stigma experiences, $F(2,198.70)$ $=0.04, p=.965$, or endorsement of the obesity stereotype about intelligence, $F(2,184.25)=1.37$,

Table 1

Descriptive statistics and bivariate correlations $(N=176)$.

\begin{tabular}{lllllll}
\hline & \multicolumn{7}{l}{ Bivariate correlation } & & \\
\cline { 3 - 6 } & $M(S D)$ & 2 & 3 & 4 & 5 & 6 \\
\hline 1. zBMI & $1.47(1.04)$ & $.397^{* *}$ & .021 & -.066 & -.145 & $-.185^{*}$ \\
2. Weight-based teasing & $1.36(0.66)$ & - & .038 & .020 & -.084 & -.128 \\
3. Stereotype on intelligence & $7.29(2.04)$ & - & - & .095 & -.091 & .071 \\
4. Working memory, Level 0 & $3.93(1.43)$ & - & - & - & $.457^{* *}$ & $.297^{* *}$ \\
5. Working memory, Level 1 & $3.35(1.74)$ & - & - & - & - & $.642^{* *}$ \\
6. Working memory, Level 2 & $1.73(1.63)$ & - & - & - & - & - \\
\hline
\end{tabular}

Note. $z$ BMI, standardized body mass index.

" Significant at .05 level (two-tailed).

** Significant at .01 level (two-tailed). 


\section{Working Memory}
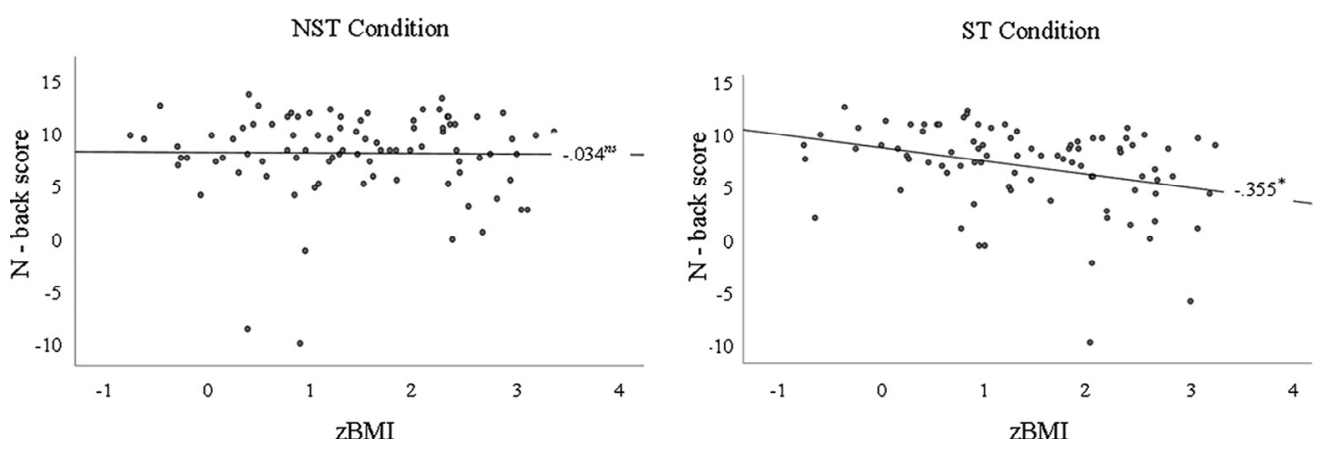

Fig. 1. Interaction between standardized body mass index (zBMI) and stereotype threat condition at $N$-back. Standardized coefficients for simple slopes are reported. NST, non-stereotype-threatening. ST, stereotype-threatening. ns, not significant. *Significant at .05 level (two-tailed).

$p=.257$. Importantly, fit indices were markedly worse when the three-way interactions among $z \mathrm{BMI}$, condition, and stigma experiences $(\triangle \mathrm{AIC}=42.706, \Delta \mathrm{BIC}=42.618)$ and among $z \mathrm{BMI}$, condition, and stereotype endorsement $(\triangle \mathrm{AIC}=21.032, \Delta \mathrm{BIC}=20.094)$ were included in the models. Supplemental analyses did not show age and gender differences or significant two-way interactions between $z \mathrm{BMI}$ and POTS or obesity stereotype endorsement.

\section{Discussion}

The current study is the first to demonstrate that the assessment of working memory in children with excess weight may yield biased results. Specifically, our findings indicate that a decrease in working memory at increasing levels of body weight emerged only when children were told that a working memory task assessed their intelligence. When concerns about the capability of the test to diagnose intelligence were removed, children with excess weight performed at levels that were indistinguishable from those of children with average weight.

We also investigated whether the negative relation between body weight and working memory was strengthened among children who had more often been the target of weight-based teasing or among those who personally avowed that children with obesity are less intelligent. Neither of these two personal characteristics emerged as a relevant moderator. Although stigma consciousness or stigma experiences may increase adults' (Brown \& Pinel, 2003) and children's (McKown \& Strambler, 2009) susceptibility to stereotype threat, these findings are in line with the general tenet that stereotype-induced performance deficits may occur even in the absence of any other aggravating factor (Aronson et al., 1999). Similarly, gender, age, and (contrary to our expectations) task difficulty did not moderate the explored relation, possibly because weight stigma equally affects boys and girls during middle childhood and may impair performance even on tasks demanding relatively low cognitive control.

Our findings concerning the role of weight-based stereotypes in hampering executive functions during middle childhood parallel prior research with adults (Guardabassi \& Tomasetto, 2018; Major et al., 2012) and have far-reaching developmental implications. Research on weight stigma during childhood is still limited to the point where this is the first study to demonstrate the role of weight-based stereotypes in hampering executive functions during middle childhood. Expanding the investigation by incorporating measures of potential outcomes of working memory depletion, such as academic achievement (Wu et al., 2017), would be useful for understanding the real-life impact of weight stigma during this developmental period. Because meta-analytic findings (Walton \& Spencer, 2009) suggest that stereotype threat also operates in ordinary school settings, it would be relevant to investigate whether obesity stigma, by impairing working memory, leads children with 
excess weight to perform below their full potential, with related spillovers on academic and career choices. This is particular relevant if we consider that children are even more likely than adults to encounter situations in which their intellectual ability is under scrutiny, ranging from school evaluation to clinical examinations. In addition, because working memory is implied in self-regulation of food intake (Houben, Dassen, \& Jansen, 2016), and preliminary evidence suggests that stereotype threat disrupts food intake control in adults with obesity (Schvey, Puhl, \& Brownell, 2011; Tomiyama, 2014), our findings lead to speculation that stereotype threat may contribute to obesity maintenance or worsening over time.

Limitations of this study should be considered. For example, the ethnic-homogeneous convenience sample of this study limits the generalization of findings to other cultural groups. In addition, measurement of potential moderators could be strengthened in future studies by including not only direct teasing by peers but also more subtle forms of stigma experience (e.g., exposure to obesity stereotypes in media) or more overt ones (e.g., bullying). Moreover, measures of weight bias internalization, which is a strong predictor of obesity-related health and psychological complications (Zuba \& Warschburger, 2017), and of implicit weight-related stereotypes should also be included in future work. This is particularly important because stereotype threat susceptibility in children may depend more on implicit attitudes and cognitions than on explicit ones (Galdi, Cadinu, \& Tomasetto, 2014). Finally, because group identification is a potential moderator of stereotype threat (Shapiro, 2011), future studies may take into account children's subjective identification with their weight status group.

In conclusion, this study offers a new explanation for the observed working memory deficits associated with childhood obesity. Researchers and clinicians should be aware that negative stereotypes attached to obesity may bias the assessment of executive functions in children with excess weight. More important, because working memory efficiency is pivotal to sustain children's psychological functioning and well-being, educational programs aimed at reducing negative societal stereotypes about obesity, as well as training interventions to help children coping with obesity stigma, should be prioritized.

\section{Acknowledgment}

This research did not receive any specific grant from funding agencies in the public, commercial, or not-for-profit sectors.

\section{Appendix A}

See Table A1.

\section{Appendix B. Experimental manipulation}

We invited children to perform the cognitive tasks in one of two experimental conditions in which we verbally manipulated the diagnosticity of the tasks with respect to intelligence.

\section{Stereotype-threatening condition}

In the stereotype-threatening (ST) condition, we labeled the experimental task as an extremely sensitive test to assess children's intelligence (i.e., a domain in which children with obesity are negatively stereotyped). The verbal instructions were as follows: "Now we are going to do some tests that are very sensitive in assessing children's intelligence. In this test, you will see a series of letters which appears in the middle of the screen ... [standard instructions for the $\mathrm{N}$-back task are provided; see Jaeggi et al., 2010, for details]. The measure of your intelligence is given by the total number of correct hits. Try to perform at your best." In Italian: "Ora andremo a fare un test al computer che ci permette di misurare molto bene quanto i bambini sono intelligenti. In questo test vedrai una serie di lettere apparire una dopo l'altra al centro dello schermo [standard instructions for the $N$-back task are pro- 
Table A1

Sample description.

\begin{tabular}{|c|c|c|}
\hline & Initial sample & Study sample \\
\hline $\begin{array}{l}\text { Number of participants } \\
z \text { BMI }\end{array}$ & $z \mathrm{BMI}$ & 176 \\
\hline Parent-reported $z$ BMI & $0.38(1.39)$ & $1.05(1.23)$ \\
\hline Measured zBMI & - & $1.47(1.04)$ \\
\hline Age (months) & $116.87(17.42)$ & $116.17(10.43)$ \\
\hline \multicolumn{3}{|l|}{$\operatorname{Sex}(\%)$} \\
\hline Male & 46.1 & 60.2 \\
\hline Female & 48.8 & 39.8 \\
\hline Missing & 5.1 & - \\
\hline \multicolumn{3}{|l|}{ Children's ethnicity (\%) } \\
\hline Born in Italy & 85.8 & 97.2 \\
\hline Born in European country & 1.2 & 1.1 \\
\hline Born in non-European country & 0.5 & 0.6 \\
\hline Missing & 12.5 & 1,1 \\
\hline \multicolumn{3}{|l|}{ Parents' ethnicity (\%) } \\
\hline Both born in Italy & 72.6 & 83.5 \\
\hline Only one born in Italy & 5 & 4.5 \\
\hline Neither born in Italy & 4.6 & 6.3 \\
\hline Missing & 17.8 & 5.7 \\
\hline Weight-based teasing ${ }^{\mathrm{a}}$ & $1.22(0.52)$ & $1.36(0.66)$ \\
\hline Stereotype on intelligence ${ }^{\mathrm{b}}$ & $6.69(3.11)$ & $7.29(2.04)$ \\
\hline \multicolumn{3}{|l|}{ Working memory $(N \text {-back })^{c}$} \\
\hline Level 0 & - & $3.93(1.43)$ \\
\hline Level 1 & - & $3.35(1.74)$ \\
\hline Level 2 & - & $1.73(1.63)$ \\
\hline
\end{tabular}

Note. Means and standard deviations (in parentheses) are reported for continuous variables. $z$ BMI, standardized body mass index.

a Weight-based teasing: range 1 (never) to 6 (almost every day).

b Stereotype on intelligence: range 1 (totally disagree) to 10 (totally agree).

c Working memory: higher scores indicate better performance (observed range: $N$-back 0: $-2.33 / 5.00 ; N$-back 1: $-5.66 / 5.00 ; N$-back-2: $-4.33 / 5.00)$.

vided; see Jaeggi et al., 2010, for details]. La misura della tua intelligenza è il totale delle tue risposte corrette. Cerca di fare il compito meglio che puoi."

\section{Non-stereotype-threatening condition}

In the non-stereotype-threatening (NST) condition, we labeled the experimental tasks as a computer game, thereby labeling the tasks as nondiagnostic of stereotype-relevant abilities (including intelligence). The verbal instructions were as follows: "Now we are going to play a computer game. In this test, you will see a series of letters which appears in the middle of the screen ... [standard instructions for the $\mathrm{N}$-back task are provided, with the word "test" being replaced by "game"; see Jaeggi et al., 2010, for details]. The score of the game is given by the total number of correct hits. Try to perform at your best." In Italian: "Ora andremo a fare gioco al computer. Vedrai una serie di lettere apparire una dopo l'altra al centro dello schermo [standard instructions for the $\mathrm{N}$-back task are provided, with the word "test" being replaced by "gioco"; see Jaeggi et al., 2010, for details]. Il punteggio del gioco è il totale delle tue risposte corrette. Cerca di fare il compito meglio che puoi."

\section{Appendix C. Supplementary material}

Supplementary data to this article can be found online at https://doi.org/10.1016/j.jecp.2019. 104706. 


\section{References}

Ambady, N., Shih, M., Kim, A., \& Pittinsky, T. (2001). Stereotype susceptibility in children: Effects of identity activation on quantitative performance. Psychological Science, 12, 385-390.

Aronson, J., Lustina, M. J., Good, C., Keough, K., Steele, C. M., \& Brown, J. (1999). When white men can’t do math: Necessary and sufficient factors in stereotype threat. Journal of Experimental Social Psychology, 35, 29-46.

Brown, R. P., \& Pinel, E. C. (2003). Stigma on my mind: Individual differences in the experience of stereotype threat. Journal of Experimental Social Psychology, 39, 626-633.

Bruce, A. S., Holsen, L. M., Chambers, R. J., Martin, L. E., Brooks, W. M., Zarcone, J. R., ... Savage, C. R. (2010). Obese children show hyperactivation to food pictures in brain networks linked to motivation, reward and cognitive control. International Journal of Obesity, 34, 1494-1500.

Chang, Y. K., Chu, C. H., Chen, F. T., Hung, T. M., \& Etnier, J. L. (2017). Combined effects of physical activity and obesity on cognitive function: Independent, overlapping, moderator, and mediator models. Sports Medicine, 47, 449-468.

Chojnacki, M. R., Raine, L. B., Drollette, E. S., Scudder, M. R., Kramer, A. F., Hillman, C. H., \& Khan, N. A. (2018). The negative influence of adiposity extends to intraindividual variability in cognitive control among preadolescent children. Obesity, 26, 405-411.

Di Pasquale, R., \& Celsi, L. (2017). Stigmatization of overweight and obese peers among children. Frontiers in Psychology, 8. https://doi.org/10.3389/fpsyg.2017.00524.

Eccles, J. S. (1999). The development of children ages 6 to 14. Future of Children, 9(2), 30-44.

Esteban-Cornejo, I., Mora-Gonzalez, J., Cadenas-Sanchez, C., Contreras-Rodriguez, O., Verdejo-Roman, J., Henriksson, P., ... Hillman, C. H. (2018). Fitness, cortical thickness and surface area in overweight/obese children: The mediating role of body composition and relationship with intelligence. Neurolmage, 186, 771-781.

Frank, M. J., Seeberger, L. C., \& O’Reilly, R. C. (2004). By carrot or by stick: Cognitive reinforcement learning in parkinsonism. Science, 306, 1940-1943.

Galdi, S., Cadinu, M., \& Tomasetto, C. (2014). The roots of stereotype threat: When automatic associations disrupt girls' math performance. Child Development, 85, 250-263.

GBD (2017). Obesity Collaborators. (2017). Health effects of overweight and obesity in 195 countries over 25 years. New England Journal of Medicine, 377, 13-27.

Goldschmidt, A. B., O’Brien, S., Lavender, J. M., Pearson, C. M., Le Grange, D., \& Hunter, S. J. (2018). Executive functioning in a racially diverse sample of children who are overweight and at risk for eating disorders. Appetite, 124, 43-49.

Guardabassi, V., Mirisola, A., \& Tomasetto, C. (2018). How is weight stigma related to children's health-related quality of life? A model comparison approach. Quality of Life Research, 27, 173-183.

Guardabassi, V., \& Tomasetto, C. (2018). Does weight stigma reduce working memory? Evidence of stereotype threat susceptibility in adults with obesity. International Journal of Obesity, 42, 1500-1507.

Guerrieri, R., Nederkoorn, C., \& Jansen, A. (2008). The interaction between impulsivity and a varied food environment: Its influence on food intake and overweight. International Journal of Obesity, 32, 708-714.

Gunstad, J., Spitznagel, M. B., Paul, R. H., Cohen, R. A., Kohn, M., Luyster, F. S., ... Gordon, E. (2008). Body mass index and neuropsychological function in healthy children and adolescents. Appetite, 50, 246-251.

Hayes, J. F., Eichen, D. M., Barch, D. M., \& Wilfley, D. E. (2018). Executive function in childhood obesity: Promising intervention strategies to optimize treatment outcomes. Appetite, 124, 10-23.

He, J., Chen, X., Fan, X., Cai, Z., \& Huang, F. (2019). Is there a relationship between body mass index and academic achievement? A meta-analysis. Public Health, 167, 111-124.

Houben, K., Dassen, F. C., \& Jansen, A. (2016). Taking control: Working memory training in overweight individuals increases selfregulation of food intake. Appetite, 105, 567-574.

Jaeggi, S. M., Studer-Luethi, B., Buschkuehl, M., Su, Y. F., Jonides, J., \& Perrig, W. J. (2010). The relationship between n-back performance and matrix reasoning-Implications for training and transfer. Intelligence, 38, 625-635.

Juvonen, J., Lessard, L. M., Schacter, H. L., \& Suchilt, L. (2017). Emotional implications of weight stigma across middle school: The role of weight-based peer discrimination. Journal of Clinical Child E Adolescent Psychology, 46, 150-158.

Kamijo, K., Khan, N. A., Pontifex, M. B., Scudder, M. R., Drollette, E. S., Raine, L. B., ... Hillman, C. H. (2012). The relation of adiposity to cognitive control and scholastic achievement in preadolescent children. Obesity, 20, $2406-2411$.

Kohler, M., Kennedy, D., Martin, J., Coussens, S., Pamula, Y., Wabnitz, D., \& Lushington, K. (2018). The influence of body mass on long-term cognitive performance of children treated for sleep-disordered breathing. Sleep Medicine, 51, 1-6.

Latner, J. D., Simmonds, M., Rosewall, J. K., \& Stunkard, A. J. (2007). Assessment of obesity stigmatization in children and adolescents: Modernizing a standard measure. Obesity, 15, 3078-3085.

Li, Y., Shang, S., Fei, Y., Chen, C., Jiang, Y., Dang, L., ... Qu, Q. (2018). Interactive relations of type 2 diabetes and abdominal obesity to cognitive impairment: A cross-sectional study in rural area of Xi'an in China. Journal of Diabetes and Its Complications, 32 , $48-55$.

Major, B., Eliezer, D., \& Rieck, H. (2012). The psychological weight of weight stigma. Social Psychological and Personality Science, 3, 651-658.

McKown, C., \& Strambler, M. J. (2009). Developmental antecedents and social and academic consequences of stereotypeconsciousness in middle childhood. Child Development, 80, 1643-1659.

Miller, A. A., \& Spencer, S. J. (2014). Obesity and neuroinflammation: A pathway to cognitive impairment. Brain, Behavior, and Immunity, 42, 10-21.

Onis, M. D., Onyango, A. W., Borghi, E., Siyam, A., Nishida, C., \& Siekmann, J. (2007). Development of a WHO growth reference for school-aged children and adolescents. Bulletin of the World Health Organization, 85, 660-667.

Ou, X., Andres, A., Pivik, R. T., Cleves, M. A., \& Badger, T. M. (2015). Brain gray and white matter differences in healthy normal weight and obese children. Journal of Magnetic Resonance Imaging, 42, 1205-1213.

Pansu, P., Régner, I., Max, S., Colé, P., Nezlek, J. B., \& Huguet, P. (2016). A burden for the boys: Evidence of stereotype threat in boys' reading performance. Journal of Experimental Social Psychology, 65, 26-30. 
Pont, S. J., Puhl, R., Cook, S. R., \& Slusser, W. (2017). Stigma experienced by children and adolescents with obesity. Pediatrics, 140 e20173034.

Prickett, C., Brennan, L., \& Stolwyk, R. (2015). Examining the relationship between obesity and cognitive function: A systematic literature review. Obesity Research \& Clinical Practice, 9, 93-113.

Raftery, A. E. (1995). Bayesian model selection in social research. Sociological Methodology, 25, 111-164.

Reilly, J. J., \& Kelly, J. (2011). Long-term impact of overweight and obesity in childhood and adolescence on morbidity and premature mortality in adulthood: Systematic review. International Journal of Obesity, 35, 891-898.

Schvey, N. A., Puhl, R. M., \& Brownell, K. D. (2011). The impact of weight stigma on caloric consumption. Obesity, 19, 1957-1962.

Schwimmer, J. B., Burwinkle, T. M., \& Varni, J. W. (2003). Health-related quality of life of severely obese children and adolescents. Journal of the American Medical Association, 289, 1813-1819.

Shapiro, J. R. (2011). Different groups, different threats: A multi-threat approach to the experience of stereotype threats. Personality and Social Psychology Bulletin, 37, 464-480.

Song, T. F., Chi, L., Chu, C. H., Chen, F. T., Zhou, C., \& Chang, Y. K. (2016). Obesity, cardiovascular fitness, and inhibition function: An electrophysiological study. Frontiers in Psychology, 7. https://doi.org/10.3389/fpsyg.2016.01124.

Spencer, S. J., Logel, C., \& Davies, P. G. (2016). Stereotype threat. Annual Review of Psychology, 67, 415-437.

Steele, C. M., \& Aronson, J. (1995). Stereotype threat and the intellectual test performance of African Americans. Journal of Personality and Social Psychology, 69, 797-811.

Thompson, J. K., Cattarin, J., Fowler, B., \& Fisher, E. (1995). The Perception of Teasing Scale (POTS): A revision and extension of the Physical Appearance Related Teasing Scale (PARTS). Journal of Personality Assessment, 65, 146-157.

Tomiyama, A. J. (2014). Weight stigma is stressful: A review of evidence for the cyclic obesity/weight-based stigma model. Appetite, 82, 8-15.

Tsai, C. L., Chen, F. C., Pan, C. Y., \& Tseng, Y. T. (2016). The neurocognitive performance of visuospatial attention in children with obesity. Frontiers in Psychology, 7. https://doi.org/10.3389/fpsyg.2016.01033.

Walton, G. M., \& Spencer, S. J. (2009). Latent ability: Grades and test scores systematically underestimate the intellectual ability of negatively stereotyped students. Psychological Science, 20, 1132-1139.

Wu, N., Chen, Y., Yang, J., \& Li, F. (2017). Childhood obesity and academic performance: The role of working memory. Frontiers in Psychology, 8. https://doi.org/10.3389/fpsyg.2017.00611.

Zuba, A., \& Warschburger, P. (2017). The role of weight teasing and weight bias internalization in psychological functioning: A prospective study among school-aged children. European Child E Adolescent Psychiatry, 26, 1245-1255. 